\title{
Safety and efficacy of a novel temporary sternal spreader in the management of severe postcardiotomy cardiogenic shock: A preliminary report study
}

\author{
Francesco Santini, MD, Francesco Onorati, MD, Giuseppe Faggian, MD, and Alessandro Mazzucco, MD, \\ Verona, Italy
}

Open chest management (OCM) with delayed sternal closure (DSC) is a valuable tool to manage patients with postcardiotomy hemodynamic instability related to cardiogenic shock with myocardial and lung edema and/or severe coagulopathy. ${ }^{1-4}$

OCM traditionally involves the use of plastic material (generally a syringe) acting as a stent between the 2 hemisternal halves, with the purposes to maintain the chest open to prevent compression and to avoid traumatic injuries on the underlying mediastinal structures. ${ }^{1-4}$ The use of these "passive" plastic stents, however, is linked to the "all or nothing" rule, which makes the decision on stent removal and chest closure tricky and potentially associated with a renewed hemodynamic instability. ${ }^{4}$ The risk for passive stent dislocation with potential sternal fracture or mediastinal injury has also been reported..$^{1-5}$

We tested a new device for temporary sternal stenting, the Temporary Sternal Spreader (TSS; Futura Engineering, Cerbara, PG, Italy), which allows "closed" remote spreading variations over time until complete reapproximation of the sternal halves is accomplished, while keeping the wound continuously covered by a sterile elastic membrane. The trial was coupled with continuous hemodynamic monitoring to titrate sternal reapproximation on objective hemodynamic improvements.

\section{CLINICAL SUMMARY}

Between December 2009 and March 2010, 5 (1.3\%) patients ( 3 male, mean age $67.8 \pm 6$ years) among those

From the Division of Cardiac Surgery, University of Verona Medical School, Verona, Italy.

Disclosures: Dr Santini is the inventor of the Temporary Sternal Spreader and has a joint ownership with Futura Engineering for the device patent.

Presented at the XXXVII Annual Meeting of the European Society for Artificial Organs, Skopje R. Macedonia, September 8-11, 2010.

Received for publication March 1, 2011; accepted for publication March 24, 2011; available ahead of print April 22, 2011.

Address for reprints: Francesco Santini, MD, Division of Cardiac Surgery, University of Verona, Piazzale Stefani 1, 37126 Verona, Italy (E-mail: francesco.santini@ univr.it).

J Thorac Cardiovasc Surg 2011;142:1276-8

$0022-5223 / \$ 36.00$

Copyright (c) 2011 by The American Association for Thoracic Surgery

doi:10.1016/j.jtcvs.2011.03.024 having 380 contemporary open cardiac procedures had refractory postcardiotomy cardiogenic shock (cardiac index $<1.5 \pm 0.2 \mathrm{~L} \cdot \mathrm{min}^{-1} \cdot \mathrm{m}^{-2}$ ) with acute hemodynamic instability at any attempt to close the chest. The new TSS was implanted in these patients. All patients shared preoperative ventricular dysfunction (mean ejection fraction $38.2 \% \pm 7 \%$ ), pulmonary hypertension (mean pulmonary artery pressures $57 \pm 5 \mathrm{~mm} \mathrm{Hg}$ ), and prolonged intraoperative cardiopulmonary bypass time (147.3 \pm 51.4 minutes).

The newly conceived TSS consists of stainless steel branches linked to 2 diverging plates of polyether ether ketone fixed to the sternal edges by interrupted sutures, whose progressive opening/closing mechanism is controlled from outside the chest by a rotating steel wire passed through the skin inside a conventional chest tube drain (Figure 1, $A, B$, and $C$ ). The external rotating steel wire approximates (clockwise rotation) or spreads (counterclockwise rotation) the sternal plates, allowing a maximal distance between the 2 diverging plates of $12 \mathrm{~cm}$ (Figure 2). TSS implantation was completed by wound coverage with a sterile membrane (Gore-Tex membrane [W. L. Gore \& Associates, Inc, Flagstaff, Ariz] or Esmark membrane [Northern Steel Group, Inc, Chicago Heights, Ill]) sutured to the skin edges. A Swan-Ganz catheter (Edwards LifeSciences, Irvine, Calif) was used to monitor progressive hemodynamic recovery (cardiac index $\geq 2.1$ $\mathrm{L} \cdot \min ^{-1} \cdot \mathrm{m}^{-2}$ ) and titrate "closed-remote" reapproximation of the sternal halves until virtual closure, considered a prerequisite for final sternal rewiring in all cases. A procedural success was defined as a complete reapproximation of the sternal halves with subsequent uneventful sternal closure and no need for implementation of inotropic support.

\section{RESULTS}

The procedure was successful in all patients without technical or infective complications (mean distance of intraoperative sternal spreading $10.8 \pm 0.8 \mathrm{~cm}$ ). Mean time from TSS implantation to sternal closure was $67 \pm 24$ hours (range, 49-93 hours). One patient showing worsening hemodynamic performance during progressive closure needed a 2-cm "remote" respreading to reestablish a stable 

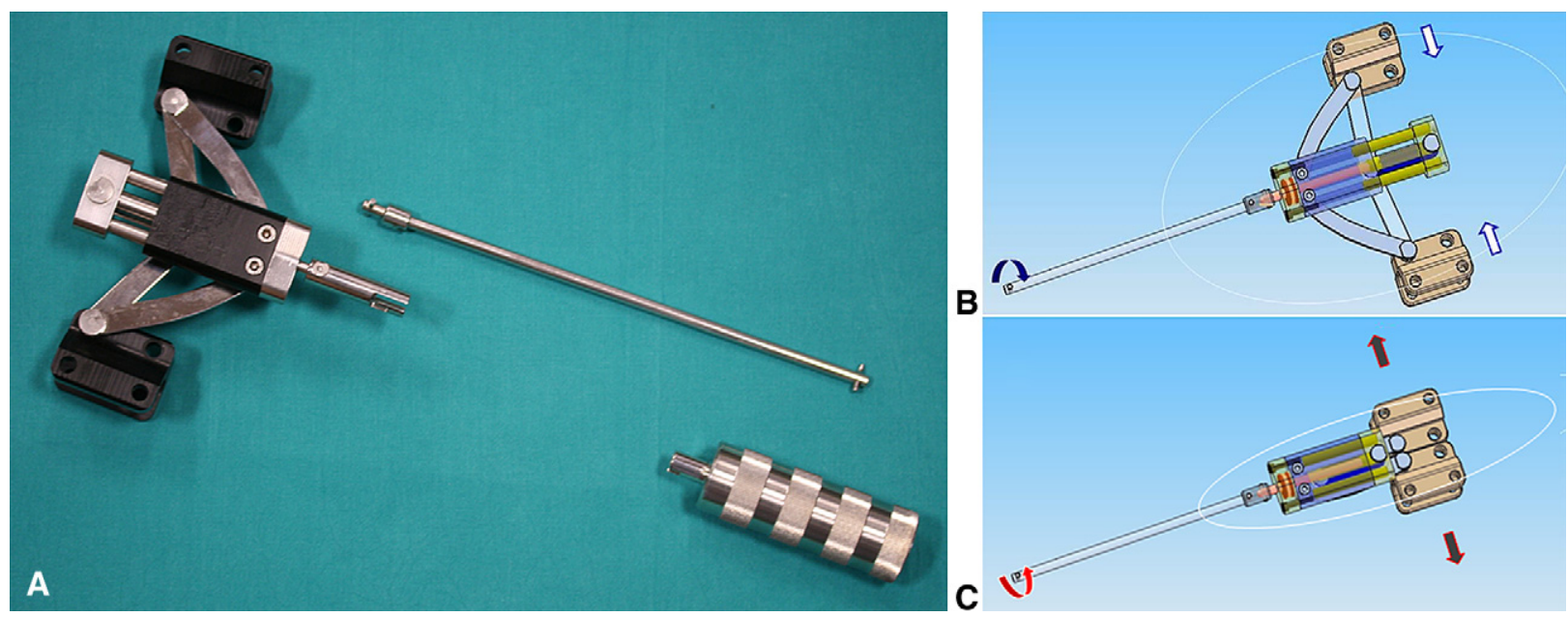

FIGURE 1. A, The TSS device (low profile spreader, rotating arm, handle). All the components are stainless steel or polyether ether ketone. The holes at the level of the sternal plates allow the device to be secured to the sternum. B, Clockwise rotation of the steel arm (curved arrow) approximates the sternal plates (straight arrows). C, Counterclockwise rotation of the steel arm (curved arrow) spreads the sternal plates (straight arrows).

hemodynamic condition. He underwent a new successful reapproximation trial 24 hours later. All patients underwent sternal closure and rewiring in the intensive care unit with no evidence of late hemodynamic instability. There was 1 $(20 \%)$ hospital death resulting from multiorgan failure on postoperative day 9 .

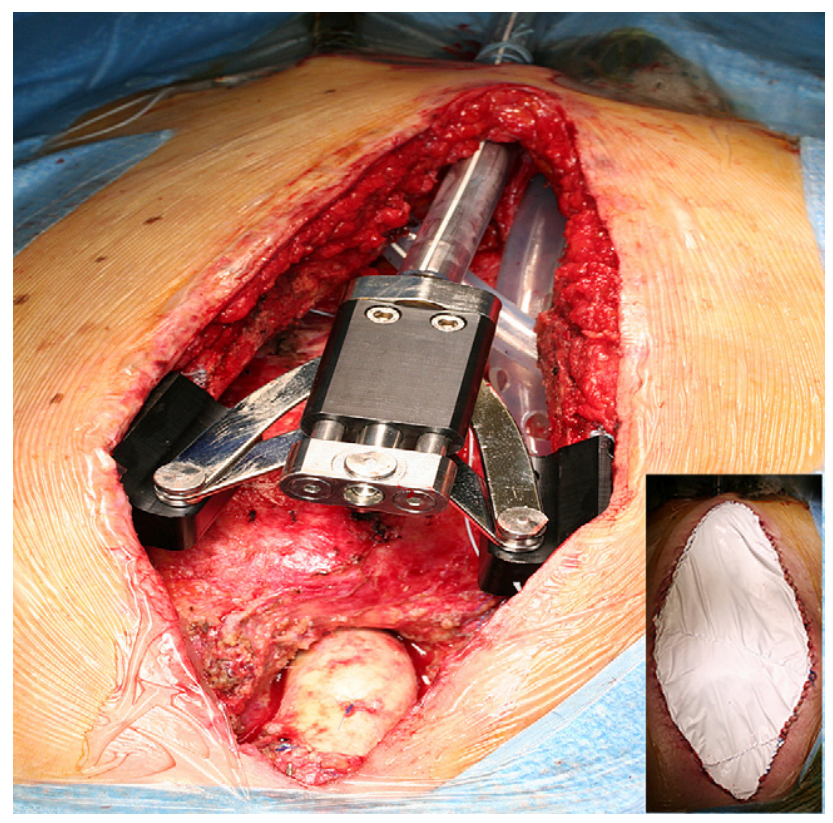

FIGURE 2. In vivo application of the TSS. Note the low profile of the spreader, which allows covering of the surgical wound by a membrane (Gore-Tex membrane [W. L. Gore \& Associates, Inc, Flagstaff, Ariz] in this case) with no bulging effect (inset).
All other patients were discharged to a rehabilitation unit. Length of intensive care unit and in-hospital stay were 197 \pm 49 hours and $16 \pm 9$ days, respectively.

\section{DISCUSSION}

OCM with DSC reported use has reached about 4\% of all cardiac cases and is thought to rise further according to a worsening referral. ${ }^{4,5}$ Currently, the use of extemporized stents made of disposable plastic materials (syringes) not approved by the Food and Drug Administration or by European CE marking is the most used method worldwide despite recognized limitations. ${ }^{1,3-5}$ The new TSS proved to be safe with no cases of sternal lesions, dislocation-related right ventricular or mediastinal injuries, or infections. Most important, the new device proved able to accommodate the progressive sternal closure to the patient-monitored hemodynamic status versus the "all or nothing" rule of other extemporized stents. Indeed, the "closed-remote" external control to achieve progressive sternal reapproximation (or spreading, if necessary) proved a very valuable tool to titrate the DSC strategy on the patient's hemodynamic improvement, also reducing the risk for mediastinal bacterial contamination by limiting the need for repeated wound dressing.

A less extemporized used of the OCM/DSC strategy in view of the availability of more sophisticated tools might allow the use of this technique to be extended to some of those patients currently managed by implantation of ventricular assist devices, for whom a less aggressive approach might be indicated with the advantage of 
preventing the potentially dismal drawbacks of mechanical assistance.

\footnotetext{
References

1. Riahi M, Tomatis LA, Schlosser RJ, Bertolozzi E, Johnston DW. Cardiac compression due to closure of the median sternotomy in open-heart surgery. Chest. 1975; 67:113-4.

2. Freeman RK, Daily PO, Dembitsky WP, Adamson RM, Moreno-Cabral RJ. The treatment of low cardiac output syndrome following cardiopulmonary bypass using delayed sternal closure. Am Surg. 1997;63:882-4.
}

3. Josa M, Khuri S, Braunwald N, Vancisin MF, Spencer MP, Evans DA, et al. Delayed sternal closure: an improved method of dealing with complications after cardiopulmonary bypass. J Thorac Cardiovasc Surg. 1986;91: 598-603.

4. Anderson CA, Filsoufi F, Aklog L, Farivar RS, Byrne JG, Adams DH. Liberal use of delayed sternal closure for postcardiotomy hemodynamic instability. Ann Thorac Surg. 2002;73:1484-8.

5. Fleck T, Kickinger B, Moidl R, Waldenberger F, Wolner E, Grabenwoger M, et al. Management of open chest and delayed sternal closure with the vacuum assisted closure system: preliminary experience. Interact CardioVasc Thorac Surg. 2008; 7:801-4.

\title{
Papillary muscle-to-anterior annulus stitches: Another technique to prevent systolic anterior motion after mitral valve repair
}

\author{
Samer Kassem, MD, ${ }^{\mathrm{a}}$ and Hicham Jamil, MD, ${ }^{\mathrm{b}}$ Milan, Italy, and Damascus, Syria
}

Mitral valve reconstruction is the procedure of choice for mitral regurgitation, with excellent early and late results. ${ }^{1}$ Systolic anterior motion (SAM) may occur after mitral valve reconstruction as a result of various anatomic factors, such as degenerative mitral insufficiency with excessive leaflet tissue, nondilated left ventricular cavity, narrow mitroaortic angle, and anterior displaced mitral coaptation line. ${ }^{2,3}$ SAM, and consequent left ventricular outflow tract obstruction, occurs in more than $16 \%$ of patients after mitral valve repair. $^{2,3}$ In this report, we describe a new method to prevent the occurrence of SAM after mitroplasty. Two artificial chords are subsequently implanted in the posterior and anterior papillary muscles, then anchored to the midanterior mitral annulus to keep the anterior leaflet away from the septum during late diastole, to prevent its displacement into the left ventricle outflow tract during systole.

\footnotetext{
From the Department of Cardiovascular Surgery, ${ }^{a}$ Centro Cardiologico Monzino I.R.C.C.S, Milan, Italy; and the Department of Cardiovascular Surgery, ${ }^{\mathrm{b}}$ Damascus University Cardiovascular Hospital, Damascus, Syria.

Disclosures: Authors have nothing to disclose with regard to commercial support.

Received for publication Feb 7, 2011; revisions received March 17, 2011; accepted for publication March 28, 2011; available ahead of print May 2, 2011.

Address for reprints: Samer Kassem, MD, Centro Cardiologico Monzino, Via Parea 4, 20138 Milan, Italy (E-mail: skassem@ccfm.it).

J Thorac Cardiovasc Surg 2011;142:1278-81

0022-5223/\$36.00

Copyright (c) 2011 by The American Association for Thoracic Surgery doi:10.1016/j.jtcvs.2011.03.025
}

\section{SURGICAL TECHNIQUE}

The inspection of the mitral valve is carried out as usual. The leaflets are accurately analyzed, and the papillary muscles are inspected to identify the posterior head of each papillary muscle. A double-armed 4-0 polytetrafluoroethylene (Gore-Tex; W. L. Gore \& Associates, Flagstaff, Ariz) suture supported by a felt pledget is passed twice through the tip of the posterior head of the posterior papillary muscle with a forehand technique and is fixed with a loose knots to avoid necrosis (Figure 1, A). The ventricular surface of the anterior leaflet is inspected with two nerve hooks to explore the attachment of 1 secondary chord, which arises from the posterior papillary muscle (preferably the most distant from the leaflet's board, and toward the mitral anteroposterior axis) (Figure 1, A). The height of the selected chord is used as a guide for determining the length of the first part of the new chord. A metal clip is placed across the 2 arms of the new chord at the level of the anchor of the stretched native chord selected (Figure 1,A). The trace of the attachment of the selected chord on the atrial surface of the anterior leaflet is determined by insertion of a thin insulin needle as a marker beside the attachment's site. Thereafter, the anterior leaflet is once again pulled down into the ventricular cavity, leaving the insulin needle in place (Figure 1, $B$ ). On the atrial surface of the anterior leaflet, the distance between the marker (the insulin needle) and the anterior annulus determines the length of the second part of the new chord, which will be anchored to the anterior annulus with no excessive tension during the presystolic phase. Multiple 